\title{
Invasive Diagnostic Testing
}

\author{
${ }^{1}$ Giovanni Monni, ${ }^{2}$ Ambra luculano, ${ }^{3}$ Cristina Peddes, ${ }^{4}$ Federica Murgia
}

\section{ABSTRACT}

Invasive diagnostic testing used for chromosomal, Mendelian, metabolic, and congenital infective diseases is represented nowadays by three main procedures: chorionic villous sampling (CVS), amniocentesis, and fetal blood sampling (FBS). The last technique due to deoxyribonucleic acid and polymerase chain reaction (DNA-PCR) analysis is ever less employed. All these techniques imply continuous ultrasound monitoring of the needle insertion in the uterus. Nondirective genetic counseling possibly before pregnancy is mandatory to explain the indications, the procedure itself, the fetal risks, the possibility for misdiagnosis and the time for receiving the results.

Although today the risks of fetal loss after CVS and amniocentesis are very low and almost equal (1:500 and 1:800), the introduction in clinical practice of the first-trimester screening by the combined test using the measurement of the fetal nuchal translucency (NT) plus hormone dosages of pregnancy-associated plasma protein (PAPP)-A and free-beta human chorionic gonadotropin (hCG) and the aid of several other soft markers, such as nasal bone, ductus venosus, and tricuspid regurgitation and above all, the recent introduction of noninvasive prenatal screening (NIPS), with analyzing cell-free DNA in the maternal blood have led to a considerable decrease of invasive diagnostic testing. This trend concerns mostly amniocentesis, whereas the importance of CVS is largely increasing, especially if in combination with comparative genomic hybridization array. The increase in CVS procedures implies a more intense request for tutoring of young fellows in the fetal medicine centers specialized in performing it. The CVS is also the procedure chosen for Mendelian and metabolic pathologies, while amniocentesis, being performed in a later period of pregnancy, is mostly employed for congenital infective diseases. In order to avoid termination of pregnancy of pathologic fetuses, the couple can opt for preimplantation genetic diagnosis (PGD), which analyzes a single or more cells of the blastomere or the blastocyst in order to transfer in utero only the healthy embryos.

Keywords: Amniocentesis, Combined screening, Fetal blood sampling, Noninvasive prenatal screening, Preimplantation genetic diagnosis, Transabdominal chorionic villous sampling, Ultrasound.

How to cite this article: Monni G, luculano A, Peddes C, Murgia F. Invasive Diagnostic Testing. Donald School J Ultrasound Obstet Gynecol 2018;12(1):52-55.

Source of support: Nil

Conflict of interest: None

\footnotetext{
${ }^{1,2}$ Professor, ${ }^{3,4}$ Specialist

${ }^{1-4}$ Department of Obstetrics and Gynecology, Prenatal \& Preimplantation Genetic Diagnosis Fetal Therapy, Microcitemico Pediatric Hospital "A. Cao", Cagliari, Sardinia, Italy
}

Corresponding Author: Giovanni Monni, Professor Department of Obstetrics and Gynecology, Prenatal \& Preimplantation Genetic Diagnosis Fetal Therapy, Microcitemico Pediatric Hospital "A. Cao", Cagliari, Sardinia, Italy, Phone: +003907052965546 e-mail: prenatalmonni@tiscali.it

\section{INTRODUCTION}

The most common invasive prenatal diagnosis to avoid birth defects can be performed before conception by polar body biopsy, before implantation by blastomere or blastocyst biopsy on more diffused in pregnancy by CVS, by amniocentesis or by FBS, by cordocentesis or intrahepatic vein puncture (Fig. 1). ${ }^{1}$

The first step in prenatal invasive procedures is nondirective genetic counseling in order to inform patients about their reproductive risks and genetic disease investigating, the familiarity of screening, diagnosis, prognosis and treatment, the risks related to the invasive procedures, their diagnostic limitations and the time for receiving the diagnosis, the modes of the procedures and all the options, including termination of pregnancy and fetal therapy. ${ }^{1}$

\section{INVASIVE DIAGNOSTIC TESTING}

\section{Chorionic Villous Sampling}

The most commonly used is transabdominal CVS (TA-CVS) with a 20-gauge spinal needle introduced by free-hand technique and under continuous ultrasound monitoring following the 10th gestational week. ${ }^{2}$ Transabdominal-CVS is more popular than the transcervical route because it can be used at any time of gestation, implies a lower risk of infections, it is easier, quicker, less painful, suggests better privacy, and is better accepted by women. ${ }^{3}$

The fetal risk, if the operator is expert in the procedure, is low (1:500-1:800) and the indications are fetal karyotype, Mendelian, and metabolic diseases. ${ }^{4}$

The most common use is following first-trimester combined screening ${ }^{5,6}$ using the ultrasound fetal NT measurement and biochemistry markers, such as PAPP-A and free beta-hCG, and after a positive cell-free DNA screening in maternal circulating blood. ${ }^{7}$ The analysis accuracy for karyotype is higher and for Mendelian diseases such as thalassemia ${ }^{8}$ and metabolic diseases, it is the technique of choice. ${ }^{9}$

\section{Amniocentesis}

It is the most common and widespread technique performed following 15 weeks of pregnancy employing the free-hand technique and a 22-gauge spinal needle under continuous ultrasound monitoring. ${ }^{10,11}$ 
Prenatal and preimplantation genetic diagnosis

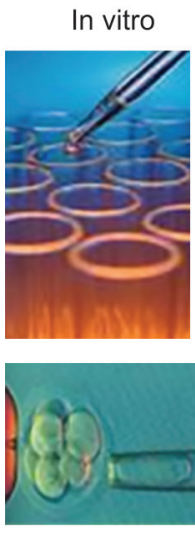

PGD

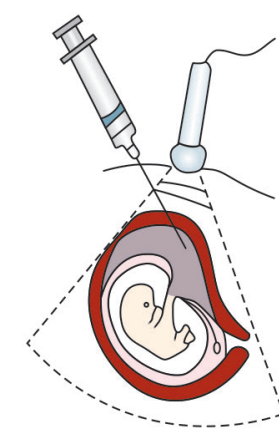

CVS

$(>10$ weeks) fetal loss $0.1-0.3 \%$

In pregnancy under ultrasound monitoring

Fig. 1: Most common invasive diagnostic testing

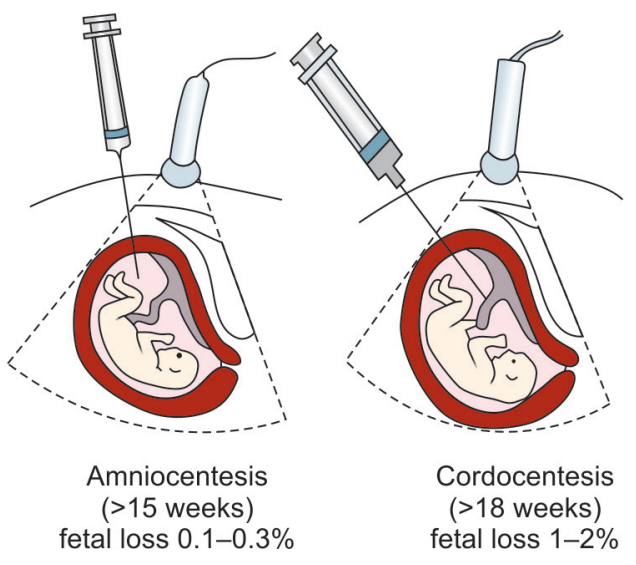

The fetal loss risk is similar to TA-CVS (1:500-1:800) $)^{11}$ and is used for karyotype analysis following first-trimester combined screening and triple/quadruple secondtrimester biochemistry screening. It is also the technique of choice for congenital infection diseases and for alfafetoprotein the diagnostic accuracy is very high. ${ }^{10}$

\section{Fetal Blood Sampling}

The most common are cordocentesis by free-hand technique and spinal 20- or 22-gauge needle introduced in the umbilical cord under continuous ultrasound monitoring. ${ }^{10}$ Meanwhile, the intrahepatic vein puncture is less used. ${ }^{11}$ The fetal risk is 1 to $2 \%$ in expert hands. The indications and the use of FBS are decreasing because of the wider use of CVS and amniocentesis for karyotype and for DNA analysis. ${ }^{12}$

\section{Transabdominal CVS and Amniocentesis}

Transabdominal CVS and amniocentesis both have the same low percentage of fetal risk and high accuracy of analysis. The CVS is preferred for early diagnosis, for Mendelian and metabolic diseases because the DNA extracted by the chorion is more accurate for the analysis. ${ }^{8}$ Also CVS is more appropriate in case of high genetic risk, and following first-trimester positive combined test ${ }^{13}$ and cell-free DNA positives. ${ }^{7}$ The TA-CVS is also the technique of choice in multiple pregnancies in case of embryo reduction or selective feticide. ${ }^{14}$ Both techniques are also used following ultrasound findings of fetal malformations. ${ }^{15}$

\section{Preimplantation Genetic Diagnosis}

When couples at high genetic risk prefer not having a child affected by genetic diseases and avoiding the possible termination of pregnancy, then PGD can be applied. ${ }^{16}$ The most used technique is the analysis of a single or more cells from the embryo and molecular analysis by DNA polymerase chain reaction or fluorescent in situ hybridization. The acceptance of PGD is very high, mostly for women who have already had a termination of pregnancy following a previous prenatal diagnosis. ${ }^{17}$

The PGD is expensive and implies the use of assisted reproduction techniques, such as in vitro fertilization and intracytoplasmic sperm injection.

\section{INVASIVE PRENATAL TECHNIQUES AND SCREENING}

The introduction of first-trimester combined screening and cell-free DNA NIPS caused an important decrease of the invasive procedures because women are reassured in case of negative or low-risk screening. ${ }^{18}$

All prenatal centers are witnessing a reduction of 30 to $70 \%$ of prenatal invasive procedures in the last 3 to 5 years and this concerns mainly amniocentesis. In our center, the decrease is about $40 \%$ and it is regarding mostly amniocentesis; in the meanwhile, TA-CVS is increasing (Graph 1).

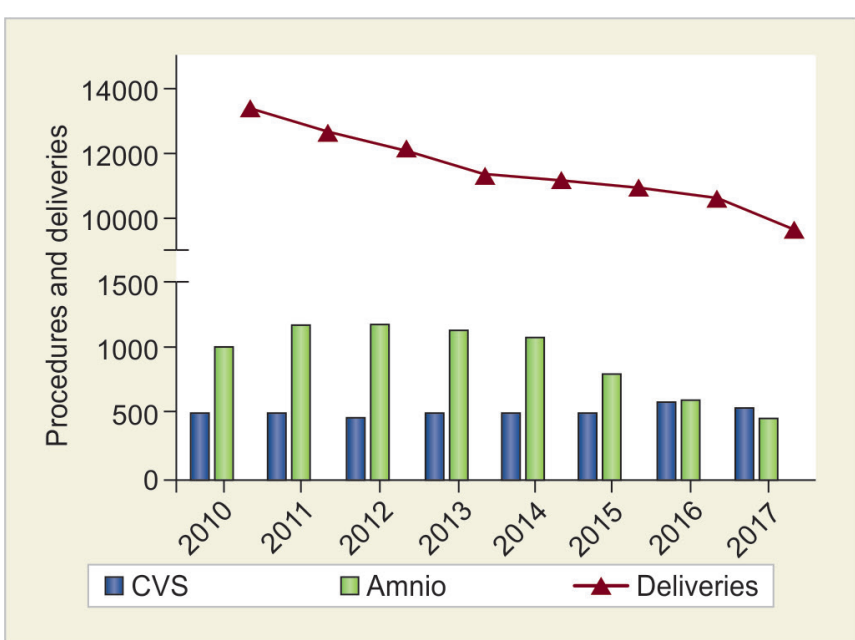

Graph 1: Prenatal invasive procedures (CVS-Amnio) according to the procedures and deliveries, Cagliari 2012 to 2017 


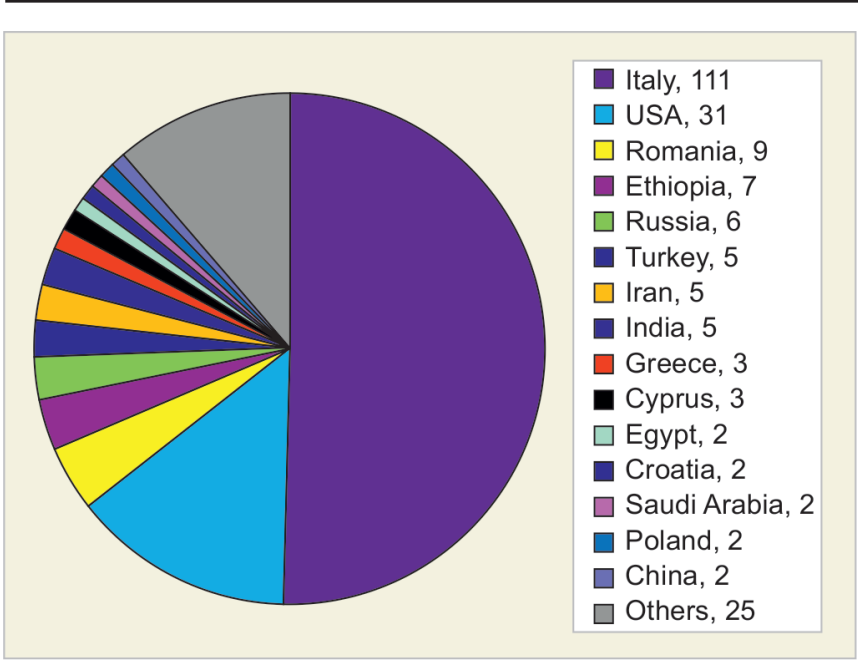

Graph 2: Fellows tutored (No 222) for CVS at Microcitemico Hospital, Cagliari from 1983 to 2018

The reduction of invasive prenatal procedures brings each year many young fellows from all over the world (Graph 2) to our center who wish to be tutored in TA-CVS and other invasive procedures. ${ }^{19}$ At the end of their training, they receive the Ian Donald School Diploma in invasive prenatal procedures (Fig. 2). ${ }^{20}$

\section{CONCLUSION}

Nowadays, invasive prenatal procedures are still in use and are essential in maternal-fetal medicine centers.

The combination between ultrasound, molecular biology, and the experience of the operator make the planning of a pregnancy more conscientious and acceptable as well as reduces the birth defects.

\section{REFERENCES}

1. Milunsky A, Milunsky JM. Genetic disorders and the fetus: diagnosis, prevention, treatment. 6th ed. Wiley-Blackwell Publisher; 2010.

2. Monni G, Zoppi MA, Ibba RM. Prenatal genetic diagnosis through chorionic villus sampling. In: Milunsky A, Milunsky JM, editors. Genetic disorders and the fetus: diagnosis, prevention, treatment. 6th ed.: Wiley-Blackwell Publisher; 2010. pp. 160-193.

3. Monni G, Olla G, Cao A. Patient's choice between transcervical and transabdominal chorionic villus sampling. Lancet 1988;1(8593):1057.

4. Monni G, Pagani G, Stagnati V, Iuculano A, Ibba RM. How to perform transabdominal chorionic villus sampling: a practical guideline. J Matern Fetal Neonatal Med 2015 Sep:1-7.

5. Nicolaides KH, Azar G, Byrne D, Mansur C, Marks K. Fetal nuchal translucency: ultrasound screening for chromosomal defects in first trimester of pregnancy. BMJ 1992 Apr;304(6831):867-869.

6. Nicolaides KH, Chervenak FA, McCullough LB, Avgidou K, Papageorghiou A. Evidence-based obstetric ethics and informed decision-making by pregnant women about invasive diagnosis after first-trimester assessment of risk for trisomy 21. Am J Obstet Gynecol 2005 Aug;193(2):322-326.

7. Gil MM, Quezada MS, Revello R, Akolekar R, Nicolaides KH. Analysis of cell-free DNA in maternal blood in screening for fetal aneuploidies: updated meta-analysis. Ultrasound Obstet Gynecol 2015 Mar;45(3):249-266.

8. Monni G, Peddes C, Iuculano A, Ibba RM. From prenatal to preimplantation genetic diagnosis of $\beta$-thalassemia. Prevention model in 8748 cases: 40 years of single center experience. J Clin Med 2018 Feb;7(2):35.

9. Monni G, Zoppi MA, Axiana C, Ibba RM. Changes in the approach for invasive prenatal diagnosis in 35,127 cases at a single center from 1977 to 2004. Fetal Diagn Ther 2006;21: 348-354.

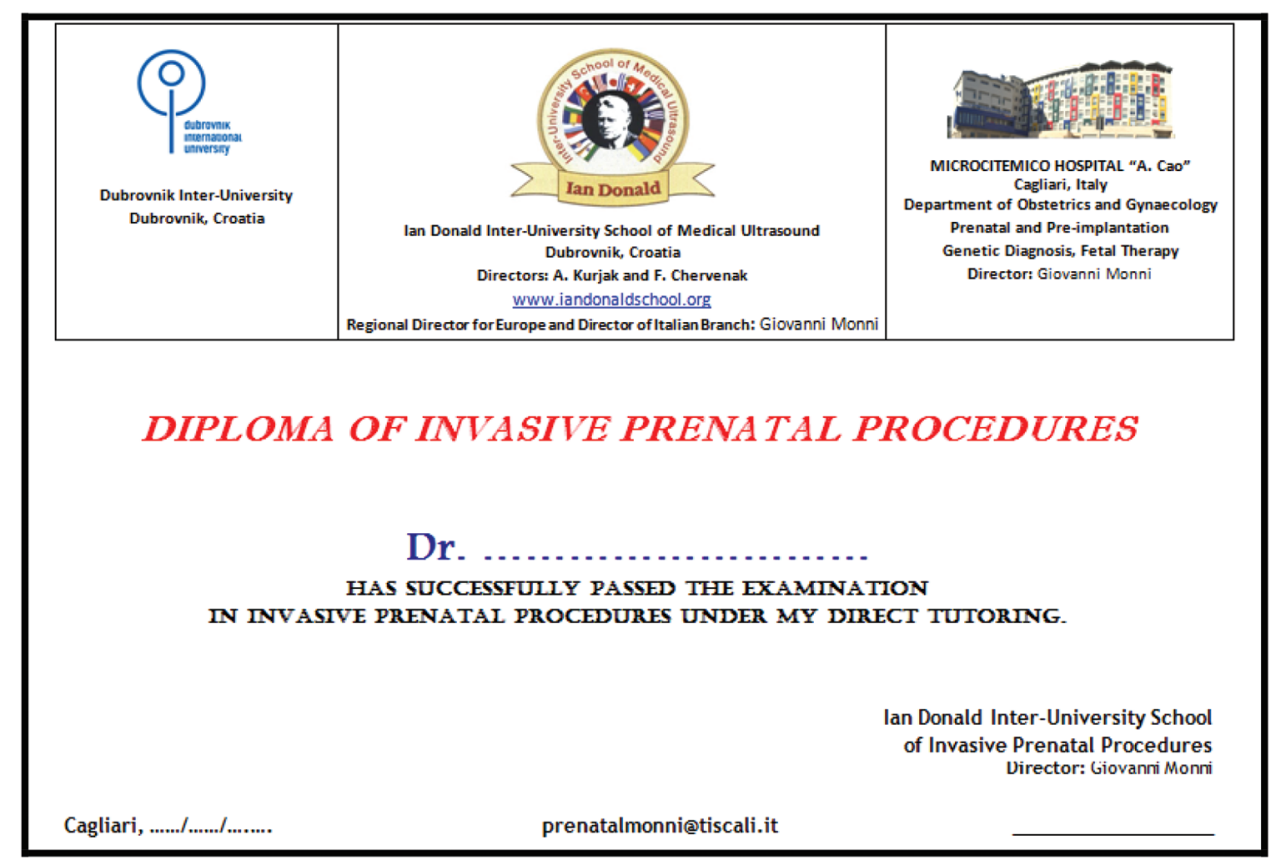

Fig. 2: Ian Donald School Diploma of invasive prenatal procedures 
10. Ghi T, Sotiriadis A, Calda P, Da Silva Costa F, Raine-Fenning N, Alfirevic Z, McGillivray G, and International Society of Ultrasound in Obstetrics and Gynecology (ISUOG). ISUOG Practice Guidelines: Invasive Procedures for Prenatal Diagnosis Ultrasound Obstet Gynecol 2016 Aug;48(2): 256-268.

11. Monni G, Iuculano A. Re: ISUOG Practice Guidelines: invasive procedures for prenatal diagnosis. Ultrasound Obstet Gynecol 2017 Mar;49(3):414-418.

12. Cao A, Cossu P, Monni G, Rosatelli C. Chorionic villus sampling and acceptance rate of prenatal diagnosis. Prenat Diagn 1987;7(7):531-533.

13. Monni G, Zoppi MA, Ibba RM, Floris M. Fetal nuchal translucency test for Down's syndrome. Lancet 1997; 350(9091): 1631-1632.

14. Monni G, Illescas T, Iuculano A, Floris M, Mulas F, McCullough LB, Chervenak FA, Gelber SE. Single center experience in selective feticide in high-order multiple pregnancy: clinical and ethical issues. J Perinat Med 2016 Mar;44(2):161-166.
15. Zoppi MA, Ibba RM, Putzolu M, Floris M, Monni G. Nuchal translucency and the acceptance of invasive prenatal chromosomal diagnosis in women aged 35 and older. Obstet Gynecol 2001 Jun;97(6):916-920.

16. Monni G, Cau G, Usai V, Perra G, Lai R, Ibba G, Faà V, Incani F, Rosatelli MC. Preimplantation genetic diagnosis for betathalassaemia: the Sardinian experience. Prenat Diagn 2004 Dec;24(12):949-954.

17. Palomba ML, Monni G, Lai R, Cau G, Olla G, Cao A. Psychological implications and acceptability of preimplantation diagnosis. Hum Reprod 1994 Feb;9(2):360-362.

18. Monni G, Zoppi MA, Iuculano A, Piras A, Arras M. Invasive or non-invasive prenatal genetic diagnosis? J Perinat Med 2014 Sep;42(5):545-548.

19. Monni G, Zoppi MA. Improved first-trimester aneuploidy risk assessment: an evolving challenge of training in invasive prenatal diagnosis. Opinion. Ultrasound Obstet Gynecol 2013 May;41(5):486-488.

20. Monni G, Pagani G, Illescas T, Stagnati V, Iuculano A, Ibba RM. Training for transabdominal villous sampling is feasible and safe. Am J Obstet Gynecol 2015 Aug;213(2):248-250. 